\title{
Lung function over the first 3 years of a professional diving career
}

\author{
Marit Skogstad, Einar Thorsen, Tor Haldorsen
}

\begin{abstract}
Objectives-To characterise diving exposure and pulmonary function in professional divers at the start of their formal education and during the first 3 years of their professional career.

Methods-The study included 87 men at the start of their education as professional divers. At follow up 1 and 3 years after the school 83 and 81 divers respectively were re-examined. Assessment of lung function included dynamic lung volumes and flows and transfer factor for carbon monoxide
\end{abstract} $\left(\mathbf{T} 1_{\mathrm{Co}}\right)$.

Results-69 Divers had preschool SCUBA diving experience and had a median number of 70 dives (range 2-3000) to a median maximal depth of 40 (range 10-73) metres. During the 15 week introductory diving course, they had 44 dives (range $38-50$ ) in the depth range $10-50$ metres. The median number of dives over the follow up period was 95 (range 0-722) to a maximal median depth of 38 (range 0-98) metres. At the start of the diving course there were no differences in forced vital capacity (FVC), forced expired volume in 1 second $\left(\mathrm{FEV}_{1}\right)$, and in $\mathrm{Tl}_{\text {co }}$ between the 69 pre-exposed divers and the 18 never exposed divers. The FVC was significantly larger than predicted in both groups. At follow up at 3 years there was a significant reduction in mean (SD) $\mathrm{FEV}_{1}$ of $1.8 \%$ (6.5), in forced mid-expiratory flow rate $\left(\mathrm{FEF}_{25-75 \%}\right)$ of $6.5 \%$ (11.7) and in forced expiratory flow at $75 \%$ of FVC expired $\left(\mathrm{FEF}_{75 \%}\right)$ of $10.4 \%$ (16.8). There was no change in $\mathbf{F V C}$. The $\mathbf{T} \mathbf{l}_{\mathrm{co}}$ was significantly decreased by $4.6 \%$ (8.8). No significant effects were found of cumulative diving exposure, including the number of dives, on the relative changes of any of the lung function variables.

Conclusions-The results indicate that divers initially belong to a selected group with large FVC. Exposure to diving may contribute to changes in pulmonary function, mostly affecting small airways conductance.

(Occup Environ Med 2000;57:390-395)

Dr Marit Skogstad

Marit.Skogstad@stami.no

Accepted 30 December 1999

Keywords: diving; follow up study; pulmonary function

Table 1 Age, height, and weight in 87 male divers (students) participating in the study including nine divers with decompression sickness or unconsciousness during follow up

\begin{tabular}{lccccc}
\hline & $\begin{array}{l}\text { All divers } \\
(n=87) \\
\text { Mean }(S D)\end{array}$ & $\begin{array}{l}\text { Previously } \\
\text { exposed }(n=69) \\
\text { Mean }(S D)\end{array}$ & $\begin{array}{l}\text { Never exposed } \\
(n=18) \\
\text { Mean }(S D)\end{array}$ & $\begin{array}{l}\text { After 3y of } \\
\text { follow up } \\
(n=81) \\
\text { Mean }(S D)\end{array}$ & $\begin{array}{l}\text { Divers who } \\
\text { subsequently had } \\
\text { accidents }(n=9) \\
\text { Mean }(S D)\end{array}$ \\
\hline Age (y) & $25.2(4.4)$ & $25.5(4.6)$ & $23.7(3.3)$ & $28.0(4.4)$ & $23.1(3.8)$ \\
Height $(\mathrm{cm})$ & $180.7(6.2)$ & $180.9(6.2)$ & $179.8(6.4)$ & $181.1(6.0)$ & $180.1(7.6)$ \\
Weight $(\mathrm{kg})$ & $79.7(10.3)$ & $80.0(10.5)$ & $78.4(9.8)$ & $82.6(9.7)$ & $77.7(13.5)$ \\
\hline
\end{tabular}

Former cross sectional studies have shown that divers have larger lungs than predicted..$^{1-3}$ Crosbie et $a l^{2}$ described a positive correlation between increased forced vital capacity (FVC) and exposure to diving up to the age of 30 years with a following decline of FVC despite continued diving. In a later study, no difference in vital capacity was found between divers, policemen, offshore workers, and the general Scandinavian population. ${ }^{4}$ In the earlier studies, ${ }^{1-3}$ the forced expired volume in 1 second $\left(\mathrm{FEV}_{1}\right)$ was not increased in proportion to the increase in vital capacity, giving a low $\mathrm{FEV}_{1} / \mathrm{FVC}$ ratio. The later study ${ }^{4}$ showed a reduction in $\mathrm{FEV}_{1}$ which correlated with the cumulative exposure to diving. This pattern of characteristics of lung function could be due to a selection of subjects with large lungs becoming divers, or an early adaptation to diving. The subsequent rates of change in FVC and $\mathrm{FEV}_{1}$ could be dependent on both the initial level of lung function and the cumulative exposure to diving. Divers may also show signs of reduced transfer factor for carbon monoxide $\left(\mathrm{Tl}_{\mathrm{CO}}\right)$ immediately after deep saturation dives ${ }^{5-7}$ when compared with a control group. ${ }^{4}$

An international consensus conference in $1993^{8}$ concluded that there is evidence that deep diving has slight but definite long term effects on the lung, including increased total lung capacity and a reduction in small airways conductance and gas transfer capacity. However, the scientific evidence was considered limited and future research, with the highest priority to longitudinal studies, was recommended.

The aim of this study was to characterise the pulmonary function and the effect of previous diving exposure at the start of a professional career for divers and to compare the measurements at the start and at the end of a 15 week introductory diving course with the results 1 and 3 years after the diving course and to see if changes could be related to diving activity during follow up.

\section{Material and methods}

THE COHORT

The divers were all male students at a diving school in the Oslo area. The school offers three courses annually, each lasting 15 weeks. The cohort was established in the period 1992-4, and included subjects from seven successive courses. All 95 students were asked to participate in the study. Two subjects who refused to participate, two female students, and four students who only participated in one pulmonary function testing during the diving course, were excluded. Thus the study included a total of 87 male divers who participated in two tests of 

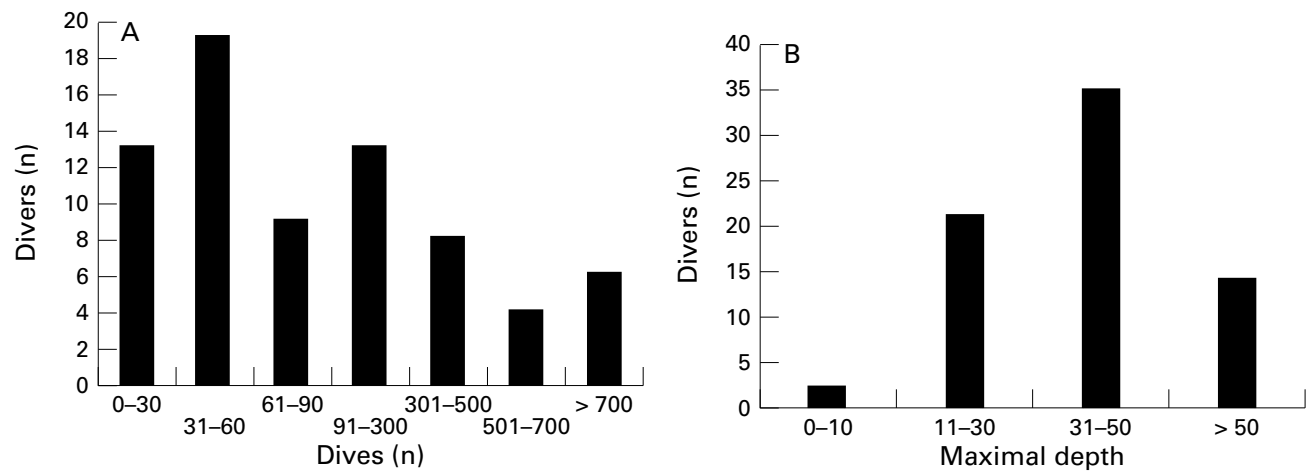

Figure 1 (A) Number of dives among 87 men before a 15 week introductory course at a school for occupational divers. (B) Maximal depths $(m)$ obtained by 87 men before a 15 week introductory course at a school for occupational divers.
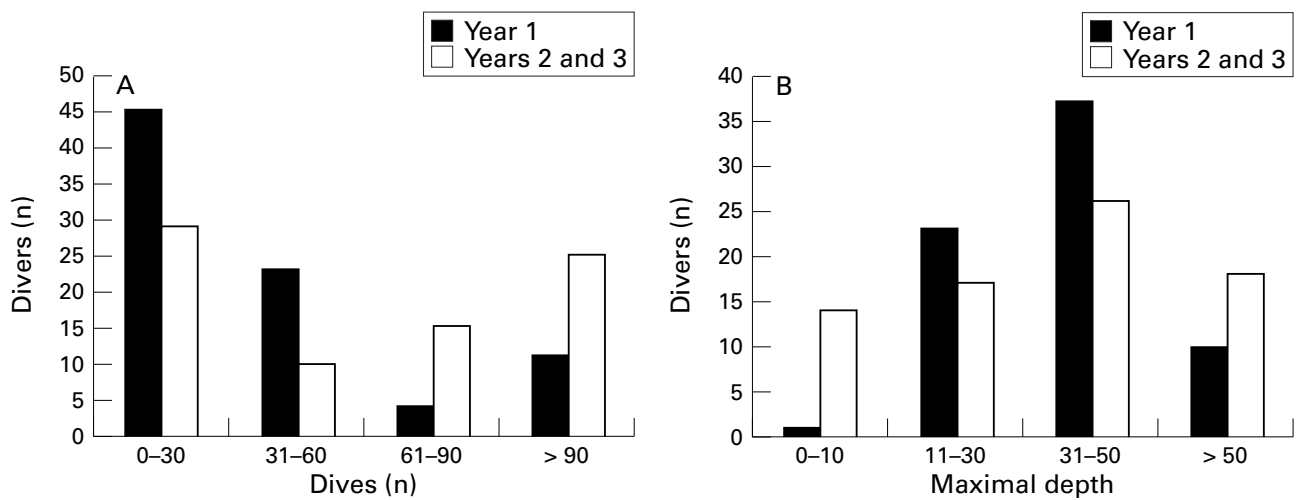

Figure 2 (A) Number of dives among 83 divers the first year of follow up (shaded bar) and 79 subjects during second and third year of follow up (filled bar). (B) Maximal depths ( $m$ ) obtained by 83 divers the first year of follow up (shaded bar) and 79 subjects during second and third year of follow up (filled bar).

pulmonary function at the start and at the end of the course (table 1). Among the 87 divers 31 $(36 \%)$ were current smokers and 20 were previous smokers. Twelve had stopped smoking within 1 year before the study and thus were considered smokers in the data analysis. At the start of the study the current smokers had smoked a mean (SD) of 5.2 (4.3) pack-years. The mean (SD) number of weekly physical training hours was 4 (3.9) at the start of the study. All divers gave written informed consent. The study is part of a multicentre study of health effects of diving, approved by the regional ethics committee for medical research both in Oslo and Bergen, Norway.

At the start of school 69 of the 87 students had SCUBA diving experience. There were no differences in smoking habits, height, weight and age between pre-exposed and never exposed divers (table 1). Eighty three divers participated in the follow up study 1 year after attending the school, and 81 in the follow up after 3 years. Those who were classified as smokers in the first study were also classified as smokers in the 1 and 3 year follow up study. Six divers were lost to follow up, among them three had moved to foreign countries. During the 3 year follow up the group of divers had a mean (SD) increase in weight from $80.0(10.4) \mathrm{kg}$ to $82.6(9.7) \mathrm{kg}$.

DIVING EXPOSURE

Previous diving exposure was registered by a questionnaire. Sixty nine subjects had a median number of 70 (range 2-3000) dives and had reached a mean (SD) maximum depth of 41 (14) metres before school (figure $1 \mathrm{~A}$ and B).

During the course diving was performed to depths of a maximum of 50 metres of sea water. The divers used air as breathing gas. Most of the diving took place during the last 11 weeks. All divers wore umbilical-type air supplied demand equipment, a Kirby Morgan band mask $18 \mathrm{~B}$ or a Kirby Morgan superlite helmet 17B and neoprene wet or dry suits. The mean (SD) time spent in the water during the diving course was 40 (5) hours and the mean number of dives was 44 (6).

Registration of diving activity during the follow up period of 3 years was not completed by all divers due to lack of registration in log books or bad memory. Diving activity was reported by 77 among 83 divers during the first year of follow up. At last follow up 67 among 81 divers

Table 2 Diving exposure among divers who subsequently had accidents $(n=9)$ and active divers without any accidents $(n=72)$

\begin{tabular}{lcl}
\hline & $\begin{array}{l}\text { Divers who } \\
\text { subsequently had } \\
\text { accidents (n=9) } \\
\text { Median (range) }\end{array}$ & $\begin{array}{l}\text { Divers without } \\
\text { accidents (n=72) } \\
\text { Median (range) }\end{array}$ \\
\hline $\begin{array}{l}\text { Before school: } \\
\quad \text { Dives (n) }\end{array}$ & $50(30-350)$ & $70(2-3000)$ \\
$\quad \begin{array}{l}\text { Deepest dive (m) } \\
\text { Follow up (year 1): }\end{array}$ & $37(20-73)$ & $38(10-70)$ \\
$\quad \begin{array}{l}\text { Dives } \\
\text { Deepest dive (m) }\end{array}$ & $27(5-422)$ & $30(4-210)$ \\
Follow up (years 2 and 3) & $108(70-300)$ & $40(10-80)$ \\
$\quad \begin{array}{l}\text { Dives (n) } \\
\text { Deepest dive (m) }\end{array}$ & $55(32-98)$ & $40(1-450)$ \\
\hline
\end{tabular}


Table 3 Results of selected lung function variables before exposure at school among 18 never exposed divers, 69 previously exposed divers and the nine divers who subsequently had accidents

\begin{tabular}{|c|c|c|c|c|c|c|}
\hline & \multicolumn{2}{|c|}{ Never exposed $(n=18)$} & \multicolumn{2}{|c|}{ Previously exposed $(n=69)$} & \multicolumn{2}{|c|}{$\begin{array}{l}\text { Divers who subsequently had } \\
\text { accidents }(n=9)\end{array}$} \\
\hline & $\begin{array}{l}\text { Absolute values } \\
\text { Mean (SD) }\end{array}$ & $\begin{array}{l}\% \text { Of predicted } \\
\text { Mean }(S D)\end{array}$ & $\begin{array}{l}\text { Absolute values } \\
\text { Mean (SD) }\end{array}$ & $\begin{array}{l}\% \text { Of predicted } \\
\text { Mean }(S D)\end{array}$ & $\begin{array}{l}\text { Absolute values } \\
\text { Mean (SD) }\end{array}$ & $\begin{array}{l}\% \text { Of predicted } \\
\text { Mean }(S D)\end{array}$ \\
\hline FVC (1) & $5.95(0.66)$ & $106.2(11.5)$ & $6.25(0.89)$ & $110.0(11.5)$ & $6.13(1.1)$ & $109.6(15.2)$ \\
\hline $\mathrm{FEV}_{1}(\mathrm{l})$ & $4.97(0.55)$ & $100.3(13.0)$ & $5.14(0.73)$ & $101.9(11.6)$ & $4.97(0.56)$ & $101.4(13.7)$ \\
\hline $\mathrm{FEF}_{25-75 \%}(1 / \mathrm{s})$ & $5.17(1.37)$ & & $5.11(1.22)$ & & $4.78(0.98)$ & \\
\hline $\operatorname{Tlco}(\mathrm{mmol} / \mathrm{min} / \mathrm{kPa})$ & $14.3(2.2)$ & $114.7(18.0)$ & $13.9(2.3)$ & $111.0(16.9)$ & $13.7(1.8)$ & $112.3(13.9)$ \\
\hline
\end{tabular}

${ }^{\star}$ According to Gulsvik et al ${ }^{9}$ and Gulsvik et al. ${ }^{10}$

reported diving activity during the preceding 2 years (fig $2 \mathrm{~A}$ ).

The median number of dives performed during the 3 year follow up was 95 (range 0-722).

The mean (SD) depth of the deepest dive performed during the first year of follow up was 40 (16) metres and during the second and third postcourse years it was 38 (20) metres. Reports of diving activity after 1 year of follow up showed that 10 had dived to a depth of $\geqslant 50$ metres. During the second and third year of follow up 18 divers reported that they had been $\geqslant 50$ metres (fig $2 \mathrm{~B}$ ).

DIVING RELATED DISEASE AND ACCIDENTS

No diver had been treated for decompression sickness (DCS) before attending the school, but one subject reported an episode of symptoms consistent with skin bends. No accidents or DCS were recorded during the time at school. Based on the divers' written statements, 10 episodes of decompression sickness (DCS) occurred in seven different divers in the follow up period of 3 years. There were four episodes of neurological DCS, including one which affected the inner ear. Three were treated by recompression in a hyperbaric chamber. Of six reported episodes among four divers of nonneurological DCS, two episodes were treated in chambers. One subject had experienced three episodes of DCS in the knee during the second and third year of follow up treated by recompression procedures in water. Two divers had been brought unconscious onshore and were treated in hospital and in chambers. The lung function of the nine divers that had endured DCS or had been unconscious in the sea during the 3 year follow up were compared with the other divers (table 1 , table 2, table 3 ).

Table 4 Selected lung function values in the 81 divers attending the 3 year examination

\begin{tabular}{|c|c|c|c|c|}
\hline & $\begin{array}{l}\text { Before school } \\
(n=81) \\
\text { Mean (SD) }\end{array}$ & $\begin{array}{l}\text { After school } \\
(n=80) \\
\text { Mean (SD) }\end{array}$ & $\begin{array}{l}1 \text { y after school } \\
(n=79) \\
\text { Mean (SD) }\end{array}$ & $\begin{array}{l}3 \text { y after school } \\
(n=81) \\
\text { Mean (SD) }\end{array}$ \\
\hline$\overline{\text { FVC (1) }}$ & $6.26(0.84)$ & $6.33(0.89)$ & $6.41(0.88)^{\star}$ & $6.31(0.92)$ \\
\hline $\mathrm{FEV}_{1}(\mathrm{l})$ & $5.17(0.67)$ & $5.18(0.71)$ & $5.22(0.75)$ & $5.07(0.69)^{\star}+\neq$ \\
\hline $\operatorname{PEF}(1 / \mathrm{s})$ & $12.52(1.80)$ & $12.56(1.92)$ & $13.23(1.80)^{\star} \dagger$ & $12.90(1.78)$ \\
\hline $\mathrm{FEF}_{25 \%}(1 / \mathrm{s})$ & $9.90(1.76)$ & $9.82(2.01)$ & $9.95(1.97)$ & $9.79(1.94)$ \\
\hline $\mathrm{FEF}_{50 \%}(1 / \mathrm{s})$ & $6.14(1.59)$ & $6.02(1.53)$ & $6.01(1.58)$ & $5.68(1.47)^{\star}+\ddagger$ \\
\hline $\mathrm{FEF}_{75 \%}(1 / \mathrm{s})$ & $2.57(0.78)$ & $2.48(0.76)$ & $2.50(0.88)$ & $2.26(0.72)^{\star}+\ddagger$ \\
\hline $\mathrm{FEF}_{25-75 \%}(1 / \mathrm{s})$ & $5.20(1.24)$ & $5.11(1.23)$ & $5.13(1.35)$ & $4.83(1.18)^{\star} \dagger \neq$ \\
\hline Tlco $(\mathrm{mmol} / \mathrm{m}$ & $14.0(2.3)$ & $13.9(2.0)$ & $14.0(2.0)$ & $13.3(1.9)^{\star} \dagger \ddagger$ \\
\hline $\mathrm{Kco}(\mathrm{mmol} / \mathrm{min} / \mathrm{kPa} / \mathrm{l})$ & $1.93(0.3)$ & $1.87(0.26)^{\star}$ & $1.84(0.24)^{\star}$ & $1.79(0.52)^{\star} \dagger$ \\
\hline VA (l) & $7.29(0.98)$ & $7.48(1.03)^{\star}$ & $7.68(1.09)^{\star} \dagger$ & $7.70(1.10)^{\star} \dagger$ \\
\hline
\end{tabular}

${ }^{\star} \mathrm{p}<0.0083 v$ before school, Bonferroni adjustment.

$\mathrm{tp}<0.0083 v$ after school, Bonferroni adjustment

$\ddagger \mathrm{p}<0.0083 v 1 \mathrm{y}$ follow up, Bonferroni adjustment
Four episodes of middle ear barotrauma during follow up were reported among three different divers.

\section{PULMONARY FUNCTION TESTS}

The pulmonary functions of divers were compared with predicted values from a reference population consisting of a healthy never smoking segment of a randomly selected population on the south western coast of Norway. ${ }^{9}{ }^{10}$ Linear models overestimate $\mathrm{FVC}$ and $\mathrm{FEV}_{1}$ in young age groups. Thus we have used the second order polynomial model of Gulsvik et al ${ }^{9}$ when we study the divers at baseline. This model shows the evolution of FVC and $\mathrm{FEV}_{1}$ with age. The FVC and $\mathrm{FEV}_{1}$ increase with age up to a peak at the age of 25-30 years, after which they decrease.

The pulmonary function testing was performed with the Jaeger MasterLab (Erich Jaeger GmbH\&CoKG, Wuerzburg, Germany). The same technician performed all tests. The divers were tested before and after the diving course and 1 and 3 years after the course. At each event lung function was measured at least 2 days after the last dive had been performed, because changes in pulmonary function has been shown shortly after open sea bounce dives. ${ }^{11}$ The subjects were given standardised instructions on the forced maximal expiratory manoeuvre, and transfer test with a demonstration of the procedures. The tests were performed with the subjects sitting in a chair breathing through a mouthpiece with a nose clip. The spirometer was calibrated by means of a 2 litre syringe twice daily and test gas calibrations were also performed twice daily with the instruments automatic calibration programme. The best results according to ATS criteria of at least three flow volume manoeuvres performed were used in the analysis. ${ }^{12}$ The peak expiratory flow rate (PEF), FVC, $\mathrm{FEV}_{1}$, forced mid-expiratory flow rate $\left(\mathrm{FEF}_{25-75 \%}\right)$, and forced expired flow rates at $25 \%, 50 \%$, and $75 \%$ of FVC expired $\left(\mathrm{FEF}_{25 \%}, \mathrm{FEF}_{50 \%}, \mathrm{FEF}_{75 \%}\right)$ were measured. The $\mathrm{Tl}_{\mathrm{CO}}$ was measured by the single breath holding method. ${ }^{13}$ Two measurements of $\mathrm{Tl}_{\mathrm{CO}}$ were taken on each occasion. The average of the two measurements was used in the analysis. Effective alveolar volume $\left(\mathrm{V}_{\mathrm{A}}\right)$ was measured simultaneously by helium dilution, and the transfer per unit effective alveolar volume $\left(\mathrm{K}_{\mathrm{CO}}\right)$ was calculated.

STATISTICS

Student's two group test, two sided was used when comparing the never exposed and 
Table 5 Selected lung function values among the 16 never exposed and 65 previously exposed divers studied at 3 years follow up

\begin{tabular}{|c|c|c|c|c|c|c|c|c|}
\hline & \multicolumn{2}{|l|}{$\begin{array}{l}\text { Before school } \\
\text { Mean (SD) }\end{array}$} & \multicolumn{2}{|l|}{$\begin{array}{l}\text { After school } \\
\text { Mean (SD) }\end{array}$} & \multicolumn{2}{|l|}{$\begin{array}{l}1 \text { y After school } \\
\text { Mean (SD) }\end{array}$} & \multicolumn{2}{|l|}{$\begin{array}{l}3 \text { yAafter school } \\
\text { Mean (SD) }\end{array}$} \\
\hline & $\begin{array}{l}\text { Never exposed } \\
(n=16)\end{array}$ & $\begin{array}{l}\text { Previously } \\
\text { exposed } \\
(n=65)\end{array}$ & $\begin{array}{l}\text { Never exposed } \\
(n=16)\end{array}$ & $\begin{array}{l}\text { Previously } \\
\text { exposed } \\
\text { (n=64) }\end{array}$ & $\begin{array}{l}\text { Never exposed } \\
(n=15)\end{array}$ & $\begin{array}{l}\text { Previously } \\
\text { exposed } \\
(n=64)\end{array}$ & $\begin{array}{l}\text { Never exposed } \\
(n=16)\end{array}$ & $\begin{array}{l}\text { Previously } \\
\text { exposed } \\
(n=65)\end{array}$ \\
\hline FVC (1) & $6.06(0.61)$ & $6.31(0.88)$ & $6.17(0.67)$ & $6.38(0.94)$ & $6.21(0.66)$ & $6.46(0.93)$ & $6.09(0.72)$ & $6.36(0.96)$ \\
\hline $\mathrm{FEV}_{1}(\mathrm{l})$ & $5.05(0.52)$ & $5.19(0.71)$ & $5.07(0.63)$ & $5.20(0.73)$ & $5.10(0.67)$ & $5.24(0.77)$ & $4.95(0.67)$ & $5.10(0.70)$ \\
\hline $\operatorname{PEF}(1 / \mathrm{s})$ & $12.2(1.5)$ & $12.6(1.9)$ & $12.6(1.8)$ & $12.6(1.9)$ & $13.3(2)$ & $13.2(1.8)$ & $12.8(1.7)$ & $13.0(1.8)$ \\
\hline $\mathrm{FEF}_{25 \%}(1 / \mathrm{s})$ & $10.2 \quad(1.57)$ & $9.83(1.81)$ & $9.73(2.04)$ & $9.84(2.02)$ & 10.1 & $9.91(1.92)$ & $9.97(2.19)$ & $9.74(1.88)$ \\
\hline $\mathrm{FEF}_{50 \%}(1 / \mathrm{s})$ & $6.19(1.67)$ & $6.13(1.58)$ & $5.95(1.82)$ & $6.04(1.47)$ & $6.05(1.92)$ & $6.00(1.51)$ & $5.59(1.78)$ & $5.71(1.39)$ \\
\hline $\operatorname{FEF}_{75 \%}(1 / \mathrm{s})$ & $2.59(0.86)$ & $2.56(0.77)$ & $2.60(1.00)$ & $2.46(0.69)$ & $2.60(1.01)$ & $2.48(0.86)$ & $2.36(0.94)$ & $2.24(0.65)$ \\
\hline $\mathrm{FEF}_{25-75 \%}(1 / \mathrm{s})$ & $5.30(1.40)$ & $5.17(1.20)$ & $5.17(1.48)$ & $5.09(1.17)$ & $5.20(1.61)$ & $5.11(1.29)$ & $4.92(1.42)$ & $4.80(1.12)$ \\
\hline $\mathrm{Tlco}(\mathrm{mmol} / \mathrm{min} / \mathrm{kPa})$ & $14.3(2.3)$ & $13.9(2.3)$ & $14.1(2.2)$ & $13.8(2.0)$ & 14.2 & 14.0 & $13.6(2.0)$ & $13.2(1.9)$ \\
\hline $\mathrm{KCO}(\mathrm{mmol} / \mathrm{min} / \mathrm{kPa} / \mathrm{l})$ & $2.04(0.26)$ & $1.91(0.28)$ & $1.95(0.25)$ & $1.85(0.26)$ & $1.90(0.24)$ & $1.83(0.24)$ & $1.86(0.25)$ & $1.77(0.57)$ \\
\hline $\mathrm{VA}_{\mathrm{A}}(\mathrm{l})$ & $7.02(0.70)$ & $7.35(1.04)$ & $7.28(0.84)$ & $7.54(1.07)$ & $7.44(0.82)$ & $7.74(1.14)$ & $7.37(0.82)$ & $7.77(1.10)$ \\
\hline
\end{tabular}

pre-exposed groups of divers. Student's $t$ test was used in the data analysis to compare the groups of divers and their predicted values. A paired $t$ test was used to study the group of divers at different times of follow up, with the Bonferroni method when multiple comparisons were made. Multiple linear regression analysis was used to study the effect of smoking habits and diving exposure (number of dives) on the relative change between the first and last lung function measurement. All tests were two sided and the data were expressed as means (SD). A significance level of 5\% was chosen. ${ }^{14}$ SPSS for Windows (SPSS 1989-92) was used in the data analysis.

\section{Results}

There was no significant difference in initial lung function variables between the 18 never exposed divers and the 69 pre-exposed divers (table 3). The lung functions of the nine divers

Table 6 Regression coefficients for number of dives and cigarette smoking on relative change of selected lung function variables of first and last measurement

\begin{tabular}{|c|c|c|c|c|}
\hline & Total dives & Smoking & Constant & $R^{2}$ \\
\hline FVC (1) & $-6.7210^{-5}$ & $-0.034^{\star}$ & $0.036^{\star}$ & 0.08 \\
\hline $\mathrm{FEV}_{1}(\mathrm{l})$ & $-7.34 \quad 10^{-5}$ & $-0.03^{\star}$ & 0.0096 & 0.076 \\
\hline $\operatorname{PEF}(1 / \mathrm{s})$ & $-1.1910^{-4}$ & -0.051 & $0.087^{\star}$ & 0.06 \\
\hline $\mathrm{FEF}_{25 \%}$ & $-2.7610^{-4}$ & -0.05 & 0.066 & 0.12 \\
\hline $\mathrm{FEF}_{50 \%}(1 / \mathrm{s})$ & $-1.6310^{-4}$ & -0.017 & -0.031 & 0.026 \\
\hline $\mathrm{FEF}_{75 \%}(1 / \mathrm{s})$ & $-5.5910^{-5}$ & -0.009 & $-0.095^{\star}$ & 0.002 \\
\hline $\mathrm{FEF}_{25-75 \%}(1 / \mathrm{s})$ & $-3.8710^{-5}$ & -0.024 & -0.049 & 0.011 \\
\hline Tlco $(\mathrm{mmol} / \mathrm{min} / \mathrm{kPa})$ & $6.5310^{-5}$ & 0.028 & $-0.074^{\star}$ & 0.031 \\
\hline $\mathrm{KCO}(\mathrm{mmol} / \mathrm{min} / \mathrm{kPa} / \mathrm{l})$ & $6.1610^{-5}$ & 0.087 & $-0.127^{\star}$ & 0.035 \\
\hline VA (l) & $-1.8610^{-5}$ & -0.012 & $0.065^{\star}$ & 0.019 \\
\hline
\end{tabular}

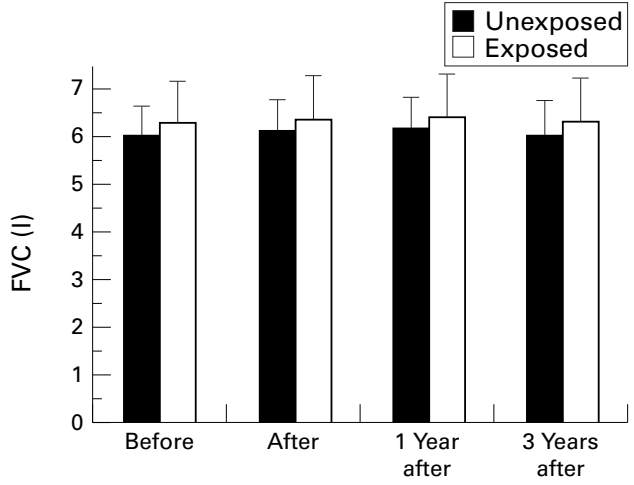

Figure 3 FVC (mean (SD)) at the start and end of school, and at 1 and 3 years of follow up among the two groups of divers who were unexposed $(n=16)$ and exposed $(n=65)$ at the start of school. who had accidents were not different from those of the other divers. Nor did we find any differences in preschool FVC, $\mathrm{FEV}_{1}$, and $\mathrm{Tl}_{\mathrm{CO}}$ between the 69 pre-exposed and the 18 never exposed divers when the results were expressed in percentage of predicted values. In both groups the initial $\mathrm{FVC}, \mathrm{FEV}_{1}$, and $\mathrm{Tl}_{\mathrm{CO}}$ values were significantly greater than the predicted values. For the pre-exposed divers we found no effect on FVC or any of the other lung function variables of any of the exposure variables on previous diving.

During the diving course there was a significant increase in $\mathrm{V}_{\mathrm{A}}$ of $2.6 \%$ (SD $5.4 \%$, $\mathrm{p}<0.001$ ) among the 87 divers, no significant change in $\mathrm{Tl}_{\mathrm{CO}}$, and a significant fall in $\mathrm{K}_{\mathrm{CO}}$ of $3.2 \%$ (SD 7.1, p<0.001). At baseline, the 43 smokers showed a significantly lower value of $\mathrm{Tl}_{\mathrm{CO}}$ compared with non-smokers, 13.2 (SD 2.3) and $14.7 \quad(\mathrm{SD} \quad 1.9) \quad \mathrm{mmol} / \mathrm{min} / \mathrm{kPa}$ $(\mathrm{p}=0.001)$ respectively. No effect of smoking on changes was found on dynamic lung volumes or gas diffusion after the 15 week follow up period.

Tables 4, 5, and 6 and figures 3-5 show the results during follow up. Table 6 shows the results in the regression model. A significant reduction in $\mathrm{FEV}_{1}$ and maximal expiratory flow rates $\left(\mathrm{FEF}_{25-75 \%}, \mathrm{FEF}_{50 \%}, \mathrm{FEF}_{75 \%}\right)$ was found when the results at 3 years follow up were compared with the results before school, after school, and at the 1 year follow up. A significantly increased $\mathrm{V}_{\mathrm{A}}$ and a significant reduction in $\mathrm{Tl}_{\mathrm{CO}}$ and $\mathrm{K}_{\mathrm{CO}}$ were also noted. However, no significant effect of cumulative diving exposure, including the number of

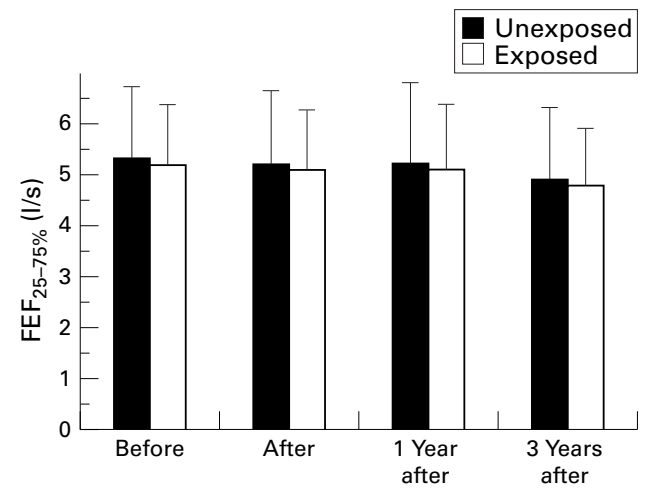

Figure $4 \mathrm{FEF}_{25-75 \%}$ (mean (SD)) at the start and end of school, and at 1 and 3 years of follow up among the two groups of divers who were unexposed $(n=16)$ and exposed $(n=65)$ at the start of school. 


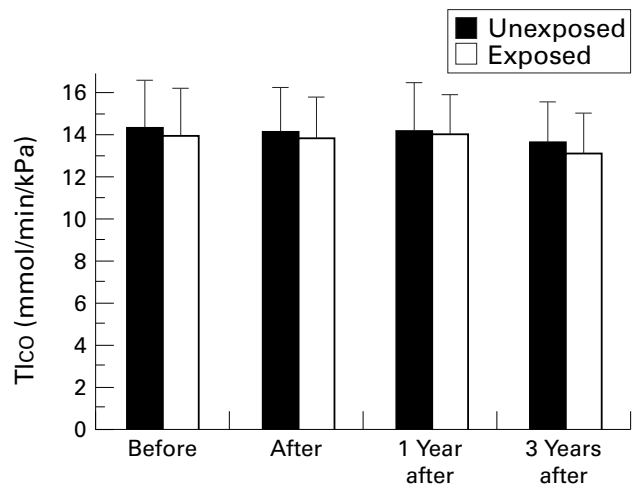

Figure $5 \quad T l_{C O}$ (mean (SD)) at the start and end of school, and at 1 and 3 years of follow up among the two groups of divers who were unexposed $(n=16)$ and exposed $(n=65)$ at the start of school.

dives, on the relative changes of any of the lung function variables was found.

The divers who were accident prone $(n=9)$ seemed to perform deeper dives and increased the number of dives during follow up compared with the divers who had no accidents during the 3 year follow up (table 2). We found no difference between the nine accident prone divers and the others when relative changes in lung function during the 3 year follow up were compared.

\section{Discussion}

This study indicates that divers have larger lungs (FVC) than predicted when they start their diving career and FVC may increase slightly due to adaptation to diving. The results may also indicate a tendency towards small airways dysfunction during the 3 year follow up period. The $\mathrm{FEV}_{1}, \mathrm{FEF}_{25-75 \%}$, and $\mathrm{FEF}_{75 \%}$ were significantly reduced and $\mathrm{V}_{\mathrm{A}}$ increased.

A larger than predicted vital capacity was found among the diving students at baseline. In the subgroup of students with previous recreational diving experience, but also among the subgroup without previous diving experience, the vital capacity was significantly different from the predicted value. ${ }^{9}$ There was, however, no significant difference between the subgroup with previous diving experience compared with the group without. The diving school has a selective intake of students based on a medical examination, and only physically fit students are accepted.

After the first year of follow up the FVC and $\mathrm{V}_{\mathrm{A}}$ were increased compared with precourse values. During this period the diving activity was most intense. The FVC between the first and third year of follow up decreased, and this could be due to less diving activity over the 2 later years of follow up. This supports the possibility of adaptation to diving. An increased FVC among divers has been reported previously by others. ${ }^{1-3}$ This has formerly been suggested as being caused either by positive selection of students ${ }^{1}$ or as a result of increasing exposure to diving. ${ }^{3}$ Increased breathing resistance due to increased gas density, ${ }^{15}$ swim training, ${ }^{16}$ and breathing equipment, could contribute to an increase in vital capacity, which could be attributed to the exercising of inspiratory muscles.

The observed changes in FVC were, however, small and have probably no clinical nor physiological significance.

There was a significant increase in $\mathrm{V}_{\mathrm{A}}$ over the 3 year observation period. This observation could reflect the normal evolution of $\mathrm{V}_{\mathrm{A}}$ with age, or it could reflect a hyperinflation due to narrowing of small airways. The normal change in $\mathrm{V}_{\mathrm{A}}$ over 3 years in this age range is not known. There is a transient increase in static lung volumes immediately after deep saturation dives, ${ }^{17}$ but in a cross sectional study of experienced saturation divers ${ }^{4}$ there was no difference in static lung volumes or $\mathrm{V}_{\mathrm{A}}$ when compared with a control group.

A change of $\mathrm{FEV}_{1}$ would not be expected among men in their early 20 s during a 3 year follow up. ${ }^{918} \mathrm{~A}$ decline in $\mathrm{FEV}_{1}$ measured by longitudinal studies is less than suggested by cross sectional studies and starts in the mid-30s among men. ${ }^{18}$ However, the reduction in $\mathrm{FEV}_{1}$ and flow rates at low lung volumes has not shown any relation to exposure to diving. Thus we might have seen the natural history of lung function over time in this highly selected group of divers. We found $\mathrm{FEV}_{1} 100 \%$ of predicted values in both groups of divers at the start of the course. However, $\mathrm{FEV}_{1}$ was significantly reduced at the 3 year follow up.

The divers also showed a loss in $\mathrm{FEF}_{25-75 \%}$ , $\mathrm{FEF}_{50 \%}$, and $\mathrm{FEF}_{75 \%} 3$ years after the diving course. A reduction in maximum expiratory flows at low lung volumes has been a consistent finding in all previous studies of divers' lung function. ${ }^{1-3} 19$ The change in flows could be an indication of small airways dysfunction, but interpretation of the index is critically dependent on the concurrent absolute lung volume. In previous cross sectional studies of divers a reduction in $\mathrm{FEF}_{75 \%}$ in divers was found when compared with other groups with the same vital capacity ${ }^{1-3}$ and same static lung volumes. ${ }^{4}$

During diving the airways could become narrowed by the external physical pressure of the distended alveoli. Subsequent chronic inflammation may appear, with thickening of the walls of the bronchioles or loss of lung elasticity, leading to dynamic compression of the airways during forced expiration. ${ }^{3}$ In a postmortem study, Calder et $a l^{20}$ have shown distension of the alveoli among eight divers in whom the ratio of $\mathrm{FEV}_{1}$ to FVC was known to be reduced.

Our findings of reduced gas transfer capacity accords with other published values that show a reduction among saturation divers after one dive of long duration where the gas transfer capacity was decreased, at least temporarily. ${ }^{5-7} 17$ In a previous study of young occupational divers performing bounce dives to shallow depths, we found that one single dive to 10 or 50 metres caused a transient reduction in gas transfer capacity, ${ }^{11}$ which nearly returned to normal within 1 week after the dive, but without knowledge of the time course in between. Other studies indicate that these changes become normal within 24 hours. ${ }^{21}$ In epidemiological studies of divers' lung function 
the time of the assessment of pulmonary function should be at least 2 days after the last dive performed, preferably more. ${ }^{21}$

The findings in the study could result from bias or systematic error. Apart from selection of divers at the start of the study, the prospective design with comparison at frequent intervals within each young diver, gives good control over the sources of bias. Also the fact that few subjects were lost to follow up minimises the possibility of errors. However, a random misclassification could be introduced as the exposure data registered in log books varied among the divers. All divers were asked to bring their log books at each follow up. Most occupational dives were logged whereas some of the recreational dives were not. However, each diver was asked to memorise his history, and to give the best information possible on depth and number of dives. In general, all dives are characterised by pressure, time, and gas mixture as the basic physical variables. Cumulative exposure to diving will therefore be strongly related to the number of dives and depths. Other derived estimates of specific exposure like hyperoxia will also be related to these basic variables. The number of dives and depths should therefore be an adequate estimate of non-specific cumulative exposure to diving.

We found no association between change in lung function and diving exposure during follow up. Former studies, reporting an association between diving exposure and change in lung function, have mostly been cross sectional studies mainly among older divers ${ }^{1-422}$ at ages 30-35 years with 6-9 years of diving experience. The present study reports small changes in lung function within a group of young divers with a limited number of dives. A longitudinal study with only 3 years of follow up would require more subjects in the study to draw any conclusions. ${ }^{23}$ However the pattern of changes occurring among the divers is the same as others have found, ${ }^{1-7}$ and the cohort will be subjected to further follow up according to the recommendations given at the international consensus conference in $1993 .{ }^{8}$

In conclusion, the results indicate that divers initially belong to a selected group with larger lung volumes than predicted. There may be an adaptation to diving with a further small increase in lung volumes. Any association between diving and airways obstruction needs further follow up.
This study was supported financially by Statoil's Fund for Research in Occupational Medicine, Oslo, Norway and The Research Council of Norway. We thank the Norwegian Commercial Diving School and Dr Helge Kjuus for excellent assistance and support.

1 Crosbie WA, Clarke MB. Physical characteristics and ventilatory function of 404 commercial divers working in the North Sea. Br F Ind Med 1977;34:19-25.

2 Crosbie WA, Reed JW, Clarke MC. Functional characteristics of the large lungs found in commercial divers. $\mathcal{F} \mathrm{Appl}$ Physiol 1979;46:639-45.

3 Davey IS, Cotes JE, Reed JW. Relationship of ventilatory capacity to hyperbaric exposure in divers. F Appl Physiol 1984;56:1655-8.

4 Thorsen E, Segadal K, Kambestad B, et al. Divers' lung function: small airways disease? Br F Ind Med 1990;47:519 23.

5 Thorsen E, Segadal K, Kambestad BK. Mechanisms of reduced pulmonary function after a saturation dive. Eur Respir f 1994;7:4-10.

6 Cotes JE, Davey IS, Reed JW, et al. Respiratory effects of a single saturation dive to $300 \mathrm{~m}$. Br f Ind Med 1987;44:76-

7 Suzuki S, Ikeda T, Hashimoto A. Decrease in the single-breath diffusing capacity after saturation dives. Undersea Biomedical Research 1991;18:103-9.

8 Hope A, Lund T, Elliott DH, et al, eds. Long term health effects of diving. Bergen, Norway: Norwegian Underwater Technology Centre, 1994.

9 Gulsvik A, Bakke P, Humerfelt S, et al. Spirometry and transfer factor for carbon monoxide in asympomatic neversmokers from a general population. In: Hope A, Lund T, Elliott DH, et al, eds. Long term health effects of diving. Bergen, Norway: Norwegian Underwater Technology Centre, gen, Norway:

1994:325-31.
0 Gulsvik A, Bakke P, Humerfelt S, et al. Single breath transfer factor for carbon monoxide in an asymptomatic population of never smokers. Thorax 1992;47:167-73.

11 Skogstad M, Thorsen E, Haldorsen T, et al. Divers' pulmonary function after open-sea bounce dives to 10 and 50 meters. Undersea Hyperb Med 1996;23:71-5.

12 American Thoracic Society. Standardization of spirometry1987 update. Am Rev Respir Dis 1987;136:1285-98.

13 American Thoracic Society. Single breath carbon monoxide diffusing capacity (transfer factor). Am Rev Respir Dis 1987;136:1299-307.

14 Altman DG. Practical statistics for medical research. London: Chapman and Hall, 1995.

15 Maio DA, Farhi LE. Effect of gas density on mechanics of breathing. F Appl Physiol 1967;23:687-93.

16 Clanton TL, Dixon GF, Drake J, et al. Effects of swim training on lung volumes and inspiratory muscle conditioning. $\mathcal{F}$ Appl Physiol 1987;62:39-46.

17 Thorsen E, Segadal K, Myrseth E, et al. Pulmonary mechanical function and diffusion capacity after deep saturation dives. Br f Ind Med 1990;47:242-7.

18 Burrows B, Lebowitz MD, Camilli AE, et al. Longitudinal changes in forced expiratory volume in one second in adults. Am Rev Respir Dis 1986;133:974-80.

19 Watt SJ. Effect of commercial diving on ventilatory function. Br f Ind Med 1985;42:59-62.

20 Calder IM, Sweetnham K, Chan KK, et al. Relation of alveolar size to forced vital capacity in professional divers. Br F Ind Med 1987;44:467-9.

21 Thorsen E, Skogstad M, Reed JW. Subacute effects of inspiratory resistive loading and head-out water immersion on pulmonary function. Undersea Hyperb Med 1999;26: $137-41$.

22 Tetzlaff K, Friege L, Reuter M, et al. Expiratory flow limitation in compressed air divers and oxygen divers. Eur Respir 7 1998;12:895-9.

23 Berry G. Longitudinal observations. Their usefulness and limitations with special reference to the forced expiratory volume. Bull Physiopathol Respir (Nancy) 1974;10:643-56. 